\title{
Acta
Biochimica
Polonica
}

Vol. 49 No. 1/2002

$221-225$

QUARTERLY

\section{In vitro activity of oxazaphosphorines in childhood acute leukemia: Preliminary report ${ }^{\star \star}$}

\author{
Jan Styczyński ${ }^{1, \bowtie}$, Mariusz Wysocki ${ }^{1}$, Robert Dębski ${ }^{1}$, Walentyna Balwierz ${ }^{2}$,
} Roma Rokicka-Milewska ${ }^{3}$, Michał Matysiak ${ }^{4}$, Anna Balcerska ${ }^{5}$, Jerzy Kowalczyk ${ }^{6}$, Jacek Wachowiak ${ }^{7}$, Danuta Sońta-Jakimczyk ${ }^{8}$ and Alicja Chybicka ${ }^{9}$

${ }^{1}$ Department of Pediatric Hematology and Oncology, Medical University, Bydgoszcz, Poland;

${ }^{2}$ Department of Pediatric Hematology, Collegium Medicum Jagiellonian University, Kraków, Poland; ${ }^{3}$ Department of Pediatric Hematology and Oncology, ${ }^{4}$ Department of Pediatric Pulmonology, Alergology and Hematology, Medical University, Warszawa, Poland; ${ }^{5}$ Department of Pediatric Hematology, Oncology and Endocrinology, Medical University, Gdańsk, Poland; ${ }^{6}$ Department of Pediatric Hematology and Oncology, Medical University, Lublin, Poland;

${ }^{7}$ Department of Pediatric Hematology and Oncology, Medical University, Poznań, Poland; ${ }^{8}$ Department of Pediatric Hematology and Chemotherapy, Silesian Medical University, Zabrze, Poland; ${ }^{9}$ Department of Pediatric Hematology and Oncology, Medical University, Wrocław, Poland

Received: 10 September, 2001; revised: 03 January, 2002; accepted: 21 February, 2002

Key words: glufosfamide, leukemia, ALL, sensitivity, resistance

Glufosfamide ( $\beta$-D-glucosyl-ifosfamide mustard) is a new agent for cancer chemotherapy. Its pharmacology is similar to commonly used oxazaphosphorines, but it does not require activation by hepatic cytochrome $P-450$ and preclinically demonstrates lower nephrotoxicity and myelosuppression than ifosfamide. The aim of the study was a comparison of the drug resistance profiles of glufosfamide and other oxazaphosphorines in childhood acute leukemias. Leukemic cells, taken from children with ALL on diagnosis $(n=41)$, ALL on relapse $(n=12)$ and AML on diagnosis $(n$

\footnotetext{
${ }^{\star}$ Presented at the 8th International Symposium on Molecular Aspects of Chemotherapy, September, 2001, Gdańsk, Poland.

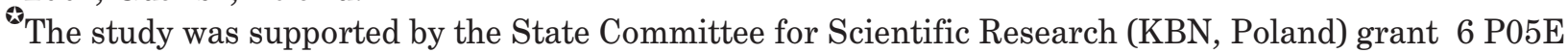
08221 and performed in the Laboratory of Clinical and Experimental Oncology, Department of Pediatric Hematology and Oncology, Medical University Bydgoszcz, Poland.

${ }^{凶}$ Address for correspondence: Jan Styczyński, W. Gersona 17-8, 85-305 Bydgoszcz, Poland; fax: (48 52) 585 4867; e-mail: jan_styczynski@kki.net.pl

Abbreviations: ALL, acute lymphoblastic leukemia; iALL, initial ALL; rALL, relapsed ALL; AML, acute myeloblastic leukemia; BM, bone marrow; CYC, 4-HOO-cyclophosphamide; GLU, glufosfamide; IFO, 4-HOO-ifosfamide; MAF, mafosfamide; $\mathrm{PB}$, peripheral blood; RR, relative resistance.
} 
= 13) were analyzed by means of the MTT assay. The following drugs were tested: glufosfamide (GLU), 4-HOO-ifosfamide (IFO), 4-HOO-cyclophosphamide (CYC) and mafosfamide cyclohexylamine salt (MAF). In the group of initial ALL samples median cytotoxicity values for GLU, IFO, CYC and MAF were 15.5, 33.8, 15.7 and 7.8 $\mu \mathrm{M}$, respectively. In comparison with initial ALL samples, the relative resistance for GLU and IFO in relapsed ALL samples was $1.9(\mathrm{p}=0.049)$ and $1.3(\mathrm{~ns})$, and in initial AML samples $31(p<0.001)$ and $5(p=0.001)$, respectively. All oxazaphosphorines presented highly significant cross-resistance. Glufosfamide presented high activity against lymphoblasts both on diagnosis and on relapse.

Oxazaphosphorines are a class of alkylating agents with a high experimental and clinical antitumor activity. Cyclophosphamide and ifosfamide are prodrugs, which need metabolic activation by cytochrome P-450 enzymes of the liver to generate the cytotoxic species [1]. The goal of search for analogues has been to synthesize "activated" oxazaphosphorines, which hydrolyze spontaneously to form primary 4-hydroxy-metabolites. However, one of those agents, mafosfamide, was difficult to develop clinically because of severe pain at the injection site, which probably resulted from acrolein generated during spontaneous degradation of the molecule during infusion [2, 3]. Glufosfamide ( $\beta$-D-glucosyl-isophosphoramide mustard) is a new agent for cancer chemotherapy with pharmacology similar to commonly used oxazaphosphorines, which does not require activation by cytochrome P-450 [4, 5]. Glufosfamide preclinically demonstrated less nephrotoxicity and myelosuppression than ifosfamide [6]. The cytotoxic activity of glufosfamide is dependent on DNA alkylating properties [4]. A more detailed analysis of the mechanism of glufosfamide action showed that the drug impaired protein and DNA synthesis, and triggered the activation of poly(ADP-ribose) polymerase (PARP), an enzyme specifically sensing DNA strand-breaks [7]. As cyclophosphamide and ifosfamide are widely used in the therapy of acute lymphoblastic leukemia (ALL), both initial (iALL) and at relapse (rALL), the objective of the study was an analysis of the drug resistance profile of glufosfamide in comparison with other oxazaphosphorines in childhood acute leukemia.

\section{MATERIALS AND METHODS}

Leukemic cells were taken from 24 girls and 42 boys, aged $0.4-18$ yrs (median 7.0 yrs) with diagnoses: initial ALL (iALL, $\mathrm{n}=41$ ), ALL on relapse ( $\mathrm{rALL}, \mathrm{n}=12$ ) and initial acute myeloblastic leukemia (iAML, $n=13$ ). Drug resistance was analyzed by means of the 4-days MTT assay [8]. Only samples with at least $80 \%$ leukemic cells in the isolate suspension were analyzed. The following drugs belonging to the group of oxazaphosphorines were tested: glufosfamide (GLU), 4-HOO-ifosfamide (IFO), 4-HOO-cyclophosphamide (CYC) and mafosfamide cyclohexylamine salt (MAF) (all provided kindly by ASTA Medica, Frankfurt, Germany) (Fig. 1, Table 1). Drug concentration lethal to $50 \%$ of tested cells $\left(\mathrm{LC}_{50}\right)$ was used as a measure of cytotoxicity. Differences between groups were compared with Mann-Whitney U test. Correlation between cytotoxicity of drugs was determined by Spearman's rho coefficient. The study was approved by the Local Ethics Committee of Medical University (Bydgoszcz, Poland).

\section{RESULTS AND DISCUSSION}

In the group of initial ALL samples, equivalent $\mathrm{LC}_{50}$ values for GLU, IFO, CYC and MAF were $15.5,33.8,15.7$ and $7.8 \mu \mathrm{M}$, respectively. The relative resistance in relapsed ALL samples, in comparison with initial ALL samples, was $1.9(p=0.049)$ for GLU and $1.3(p>0.05)$ for IFO. The group of initial AML samples was 31-fold more resistant ( $p<0.001$ ) to GLU and 5 -fold $(p=0.001)$ to IFO than iALL samples 


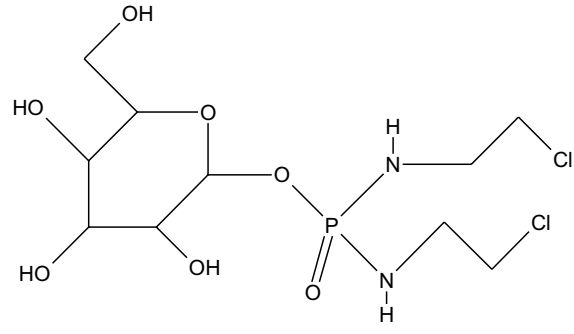

GLUFOSFAMIDE

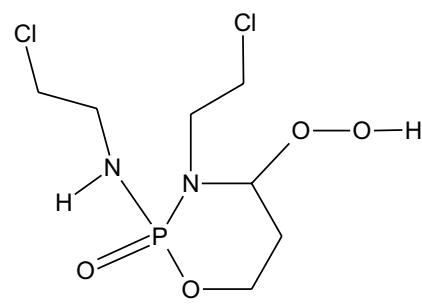

4-HYDROPEROXY-IFOSFAMIDE

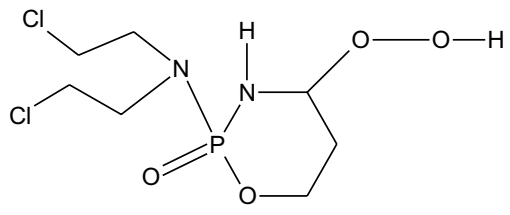

4-HYDROPEROXY-CYCLOPHOSPHAMIDE

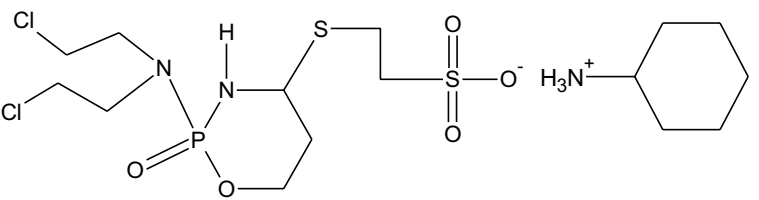

MAFOSFAMIDE CYCLOHEXYLAMINE SALT

Figure 1. Chemical structure of oxazaphosphorines.
(Table 2). All oxazaphosphorines showed highly significant cross-resistance within each pair of drugs (Table 3).

Glufosfamide shows similarity to ifosfamide in its cytotoxic effects, due to the formation of ifosfamide mustard, a metabolite of both compounds [7]. Glufosfamide is chemically stable, but can be split by intracellular glycolytic enzymes [5]. Its selectivity for tumor cells is probably due to active transport by glucose carriers. Yet the toxicity of glufosfamide for white blood cells, colony forming units and spleen colony forming units is considerably lower compared with ifosfamide. Side effects in the urinary tract are avoided, since no acrolein is formed. Free acrolein is responsible for the severe side effects in the urinary tract that are typical for this class of alkylating agents [4]. Another important difference between these drugs is that it was possible to provoke resistance of $\mathrm{SKOV}_{3}$ cells to continuous treatment with ifosfamide but not to glufosfamide [7].

We tested if glufosfamide might be able to circumvent resistance to cyclophosphamide and ifosfamide in samples of childhood acute leukemias. Glufosfamide presented a favourable cytotoxicity profile in ALL cells both on diagnosis and at relapse. However, cross-resistance with other oxazaphosphorines and other tested drugs was observed. Should the toxicity profile be taken into account, this drug might be considered useful in future clinical practice. Since cyclophosphamide is often used in the conditioning regimen before allogenic or autologous hemopoietic stem cell transplantation, and mafosfamide is used for

Table 1. Concentration ranges of the drugs tested

\begin{tabular}{lll}
\hline & $\begin{array}{l}\text { Molecular mass } \\
{[\mathrm{g} / \mathrm{mol}]}\end{array}$ & $\begin{array}{l}\text { Concentration range } \\
{[\mu \mathrm{M}]}\end{array}$ \\
\hline Glufosfamide & 383.16 & $0.50-522.0$ \\
4-HOO-ifosfamide & 293.10 & $0.33-341.2$ \\
4-HOO-cyclophosphamide & 293.10 & $0.33-341.2$ \\
Mafosfamide & 500.45 & $0.19-200.0$ \\
\hline
\end{tabular}


Table 2. Median cytotoxicity $\left(\mathrm{LC}_{50}\right)$ and relative resistance $(\mathrm{RR})$ values

\begin{tabular}{lllllc}
\hline & \multicolumn{3}{l}{${\text { Median } \mathrm{LC}_{50}[\mu \mathrm{g} / \mathrm{ml}]}$} & \multicolumn{2}{l}{ Relative resistance, $\mathrm{p}$-value } \\
\hline & iALL & $\mathrm{rALL}$ & $\mathrm{iAML}$ & $\mathrm{RR}\left(\mathrm{rALL} / \mathrm{iALL}{ }^{*}\right.$ & $\mathrm{RR}(\mathrm{iAML} / \mathrm{iALL})^{* *}$ \\
Glufosfamide & 5.95 & 11.41 & 189.7 & $1.9 ; \mathrm{p}=0.049$ & $31 ; \mathrm{p}=0.000$ \\
4-HOO-ifosfamide & 9.92 & 13.69 & 55 & $1.3 ; \mathrm{p}>0.050$ & $5.0 ; \mathrm{p}=0.001$ \\
4-HOO-cyclophosphamide & 4.6 & 7.82 & 40.02 & $1.7 ; \mathrm{p}>0.050$ & $8.7 ; \mathrm{p}=0.015$ \\
Mafosfamide & 3.9 & 23.4 & 46.8 & $6.0 ; \mathrm{p}=0.001$ & $12 ; \mathrm{p}=0.000$ \\
\hline
\end{tabular}

RR, relative resistance in comparison with iALL; $\left(^{*}\right) \mathrm{RR}$ is the median $\mathrm{LC}_{50}$ for rALL divided by the median $\mathrm{LC}_{50}$ for iALL; $\left({ }^{* *}\right)$ $\mathrm{RR}$ is the median $\mathrm{LC}_{50}$ for $\mathrm{iAML}$ divided by the median $\mathrm{LC}_{50}$ for $\mathrm{iALL}$; $\mathrm{RR}>1$ indicates that for the given drug, rALL (iAML) is more resistant than iALL; p, Mann-Whitney U test.

Table 3. Correlation matrix of cross-resistant cytotoxicity (expressed by $\mathrm{LC}_{50}$ values)

\begin{tabular}{lllll}
\hline & GLU & IFO & CYC & MAF \\
\hline GLU & & 0.619 & 0.749 & 0.777 \\
& & $<0.001$ & $<0.000$ & $<0.001$ \\
IFO & 0.619 & & 0.880 & 0.846 \\
& $<0.001$ & & $<0.001$ & $<0.001$ \\
CYC & 0.749 & 0.880 & & 0.906 \\
& $<0.001$ & $<0.001$ & & $<0.001$ \\
MAF & 0.777 & 0.846 & 0.906 & \\
& $<0.001$ & $<0.001$ & $<0.001$ & \\
\hline
\end{tabular}

Upper number in each field is the value of Spearman's rho coefficient of correlation of $\mathrm{LC}_{50}$ values for a pair of drugs, lower number - p-value of this coefficient. GLU, glufosfamide; IFO, 4-HOO-ifosfamide; CYC, 4-HOO-cyclophosphamide; MAF, mafosfamide

bone marrow purging [9], it seems that with its cytotoxicity profile glufosfamide might be also used in transplantation procedures in acute lymphoblastic leukemia. On the other hand, very weak activity of glufosfamide was observed against AML cells, typical also for other drugs belonging to this group. Concluding, the in vitro activity of glufosfamide is comparable to other oxazaphosphorines. Glufosfamide shows high activity against lymphoblasts both on diagnosis and on relapse, but because of high cross-resistance it cannot circumvent resistance to other oxazaphosphorines.

Authors thank Beata Kołodziej for technical assistance.

\section{R E F E R E N C E S}

1. Brock, N., Hilgard, P., Peukert, M., Pohl, J. \& Sindermann, H. (1988) Basis and new developments in the field of oxazaphosphorines. Cancer Invest. 6, 513-532.

2. Hilgard, P. \& Pohl, J. (1986) Short communication: Cause and prevention of mafosfamide-induced venous pain. Invest. New Drugs 4, 373-376.

3. Niemeyer, U., Engel, J., Hilgard, P., Peukert, M., Pohl, J. \& Sindermann, H. (1989) Mafosfamide - a derivative of 4-hydroxycyclophosphamide. Prog. Clin. Biochem. Med. 9, 35-60.

4. Pohl, J., Bertram, B., Hilgard, P., Nowrousian, M.R., Stuben, J. \& Wiessler, M. (1995) D-19575 - a sugar-linked isophosphoramide 
mustard derivative exploiting transmembrane glucose transport. Cancer Chemother. Pharmacol. 35, 364-370.

5. Stuben, J., Port, R., Bertram, B., Bollow, U., Hull, W.E., Schaper, M., Pohl, J. \& Wiessler, M. (1996) Pharmacokinetics and whole-body distribution of the new chemotherapeutic agent beta-D-glucosylisophosphoramide mustard and its effects on the incorporation of [methyl-3H]-thymidine in various tissues of the rat. Cancer Chemother. Pharmacol. 38, $355-365$.

6. Veyhl, M., Wagner, K., Volk, C., Gorboulev, V., Baumgarten, K., Weber, W.M., Schaper, M., Bertram, B., Wiessler, M. \& Koepsell, H. (1998) Transport of the new chemotherapeutic agent beta-D-glucosylisophosphoramide mustard (D-19575) into tumor cells is mediated by the Na+-D-glucose cotransporter SAAT1. Proc. Natl. Acad. Sci. U.S.A. 95, 2914-2919.
7. Seker, H., Bertram, B., Burkle, A., Kaina, B., Pohl, J., Koepsell, H. \& Wiesser, M. (2000) Mechanistic aspects of the cytotoxic activity of glufosfamide, a new tumour therapeutic agent. Br. J. Cancer 82, 629-634.

8. Styczyński, J., Pieters, R., Huismans, D.R., Schuurhuis, G.J., Wysocki, M. \& Veerman, A.J.P. (2000) In vitro drug resistance profiles in adult versus childhood acute lymphoblastic leukemia. Br. J. Haematol. 110, 813-818.

9. Makrynikola, V., Kabral, A. \& Bradstock, K.F. (1991) Effect of mafosfamide (ASTA-Z-7654) on the clonogenic cells in precursor-B acute lymphoblastic leukaemia: Significance for ex vivo purging of bone marrow for autologous transplantation. Bone Marrow Transplant. 8, 351-355. 